\title{
Descolonizar la formación de profesores a través de redes entre escuelas y universidades
}

\section{Decolonizing teacher training through networks between schools and universities}

\section{Decolonizando a formaçãode professores através de redes entre escolas e universidades}

\section{Sueli de Lima Moreira ${ }^{1}$}

Faculdade de Formação de Professores

da Universidade do Estado do Rio de

Janeiro, Brasil.

1 Orcid: https://orcid.org/0000-0002-35511-9007 Sueli de Lima Moreira é professora na Faculdade de Formação de Professores da Universidade do Estado do Rio de Janeiro. Doutora em Educação pela Universidade de São Paulo. Membro da Rede Ibero-americana de Pedagogia e da Rede Internacional de Investigação-Ação Colaborativa. Investiga as epistemologias da formação docente, articulando escolas e universidades em trabalhos conjuntos. Atualmente, realiza pós-doutoramento no Centro de Estudos Sociais na Universidade de Coimbra. Textos disponíveis em: $<$ https://suelidelimamoreira.wordpress.com/> .

e-mail: limamoreirasueli@gmail.com

\section{RESUMO}

Apresenta-se processo e resultado de uma investigação colaborativa realizada por um grupo de professores de escolas e universidades públicas, entre 2015 e 2018, no Brasil, período marcado por fortes perdas de direitos sociais e políticos no país. Com o objetivo de investigar as epistemologias da formação docente, articulou- 
se pesquisa ao cotidiano escolar, em especial no estudo da implementação da Base Nacional Comum Curricular (BNCC). A metodologia adotada foi a Pesquisa-Ação Pedagógica (PAPe) de Franco (2016), que assume uma perspectiva eminentemente pedagógica, pois estuda as práticas educacionais por meio da participação dos próprios sujeitos. Os resultados indicam caminhos epistemológicos decoloniais para a formação docente através do desenvolvimento de uma cultura pedagógica dialógica entre escolas e universidades.

PALAVRAS-CHAVE: pedagogia decolonial, formação de professores, escola\&universidade, pesquisa-ação.

\section{RESUMEN}

Este documento presenta el proceso y los resultados de una investigación colaborativa llevada a cabo por un grupo de docentes de escuelas públicas y universidades, entre 2015 y 2018, en Brasil, un período marcado por una fuerte pérdida de derechos sociales y políticos en el país. Para investigar las epistemologías de la formación del profesorado, la investigación se articuló a la rutina escolar, especialmente en el estudio de la implementación de la Base Nacional Curricular Común (BNCC). La metodología adoptada fue la Investigación de Acción Pedagógica Franco (PAPe) (2016), que asume una perspectiva eminentemente pedagógica, ya que estudia las prácticas educativas a través de la participación de los propios sujetos. Los resultados indican caminos epistemológicos decoloniales para la formación del profesorado mediante el desarrollo de una cultura pedagógica dialógica entre escuelas y universidades.

PALABRAS CLAVE: pedagogía decolonial, formación del profesorado, escuela y universidad, investigación en acción.

\section{ABSTRACT}

This paper presents the process and results of a collaborative investigation carried out by a group of teachers from public schools and universities, between 2015 and 2018, in Brazil, a period marked by strong loss of social and political rights in the country. In order to investigate the epistemologies of teacher education, research was articulated to the school routine, especially in the study of the implementation of the Common National Curriculum Base (BNCC). The methodology adopted was the Franco Pedagogical Action Research (PAPe) (2016), which assumes an eminently pedagogical perspective, as it studies educational practices through the participation of the subjects themselves. The results indicate decolonial epistemological paths for teacher education through the development of a dialogical pedagogical culture between schools and universities.

KEYWORDS: decolonial pedagogy, teacher education, school and university, action research.

\section{APRESENTAÇÃO}

...fazemos parte de uma grande força... compartilhando a compreensão de que, atualmente, é a forma neoliberal do capitalismo que destroça a vida, os corpos e os sonhos de bilhões. E que podemos substituí-lo (Hill, 2003, p. 47).

O trabalho apresenta uma pesquisa realizada por um grupo de professores de escolas e universidades públicas, entre 2015 e 2018, impulsionada pela necessidade de enfrentamento, em conjunto, de diversos desafios que marcaram o período para a educação no Brasil. Inicialmente através de um projeto de extensão, o grupo, autointitulado Coletivo Investigador, teve como objetivo investigar as epistemologias da formação docente, articulando a pesquisa ao cotidiano escolar, em especial as condições da implementação de uma política 
curricular no Brasil, a Base Nacional Comum Curricular (BNCC). A metodologia adotada foi a Pesquisa-Ação Pedagógica (PAPe) de Franco (2016), que assume uma perspectiva eminentemente pedagógica, pois estuda as práticas educacionais por meio da participação dos próprios sujeitos, agindo no campo da formação dos envolvidos, transformando-os. Os resultados indicam caminhos epistemológicos decoloniais para a formação docente através do desenvolvimento de uma cultura pedagógica fundamentada na cooperação e solidariedade, através de trabalhos conjuntos em ambientes democráticos. Confirma-se que a escola precisa da articulação com a universidade para legitimar-se como campo de reflexão crítica no enfrentamento dos ataques que sofre. Tal raciocínio também vale para as licenciaturas das universidades públicas, estas precisam da escola para desenvolver uma formação socialmente referenciada.

$\mathrm{O}$ artigo está dividido em cinco partes. $\mathrm{Na}$ primeira, apresentamos o contexto de ataques e lutas em que a educação pública viveu no Brasil após a destituição da presidenta eleita Dilma Rousseff, em 2015, sendo concluído em 2016. Desde esse período o país vive uma vertiginosa quebra das condições institucionais, em especial o direito à educação pública, laica e gratuita. $\mathrm{Na}$ segunda, debatemos alguns aspectos referentes aos desafios epistêmicos na perspectiva decolonial na pedagogia, questionando a marca colonial na relação com os saberes e na cultura escolar. E destacamos o perfil socioeducacional dos pesquisadores que integram o Coletivo Investigador, procurando amplificar a voz de professores sul-americanos em busca de formação e resistência política. $\mathrm{Na}$ terceira parte, indicamos nossa escolha pela Pesquisa-ação Pedagógica como opção para uma pedagogia decolonial. $\mathrm{Na}$ quarta, discorremos sobre a pesquisa, que teve como objetivo o estudo das condições de que dispunham as escolas na ocasião da implementação de uma das principais políticas de controle docente, a BNCC. Na quinta e última. apresentamos as considerações que apreendemos desse processo de investigação coletiva através do qual emergem condições para uma práxis decolonial nas relações entre escolas e universidade.

\section{O DESMONTE DA EDUCAÇÃO NO BRASIL PÓS-GOLPE DE 2015}

Em 2016, com a destituição da presidenta eleita, Dilma Rousseff, o Brasil foi marcado por um grave revés no seu processo social. $O$ feito mostrou que o Brasil, outra vez, seria tutelado por grupos poderosos indiferentes aos direitos do povo e à democracia. $O$ governo que tomou o país após o golpe começou a implementar, em ritmo acelerado, diversas medidas de restrição de direitos sem diálogo com a sociedade e indiferente às reações populares, que não foram poucas. "Se a democracia é entendida como tendo o objetivo de ampliar a capacidade de influência popular sobre as decisões públicas, então o processo em curso no Brasil pode ser definido como desdemocratização" (Miguel, 2018, p. 7). De uma só vez, a soberania popular e as leis reunidas na Constituição de 1988 foram desconsideradas (Brasil, 1988). Segundo Miguel (2018), a democracia não é um ponto de chegada, mas o conflito em torno dela entre aqueles que querem domá-la (tornando-a compatível à reprodução das desigualdades) e aqueles que, ao contrário, têm o objetivo de usá-la para acirrar as contradições e avançar no combate às desigualdades.

Nesse contexto, no qual a resistência se torna uma via importante para os que combatem as dominações, é que se situa este trabalho. Impossível não articularmos as relações entre a dominação que se impõe ao povo brasileiro e as lutas docentes, em que professores e estudantes são sucessivamente perseguidos em suas reivindicações, pensando em que sentido as derrotas sucessivas deste 
grupo de trabalhadores são impactadas pela desvalorização crescente de seu fazer profissional nas políticas neoliberais. Sob condição de dominação, vivemos, também coletivamente, dificuldades em compreender e enfrentar as situações que vivenciávamos, do contrário, não seria dominação, nos ensina Miguel (2018). Como levar adiante a luta docente num contexto em que a multiplicidade de ataques é efetivada num curto espaço de tempo, refletindo-se em distintas frentes? O que podem fazer os professores para não se deixarem paralisar diante da ausência de um projeto democrático para a educação nos sistemas educacionais em que atuam?

O país viveu após a reeleição da presidenta Dilma Rousseff uma vertiginosa quebra das condições institucionais, sua destituição (2016) levou a um aprofundamento das condições políticas, que se expressaram rapidamente no aumento da desigualdade social, perseguição aos direitos, ausência de diálogo. E na Educação, na implementação de diversas políticas autoritárias.

O desmonte da Educação Pública corresponde ao desmonte da maior política pública brasileira: em todo dia letivo, quase 40 milhões de estudantes vão às escolas públicas de educação básica em todo país e mais de 1 milhão de jovens estudam nas universidades administradas pelos governos. Quando chegam às suas escolas e faculdades, os estudantes são recebidos por, aproximadamente, 5 milhões de educadoras e educadores, que desempenham diferentes funções para a manutenção e desenvolvimento do ensino (Cara, 2018). A política educacional brasileira é de grande porte e se for bem-sucedida, ela tem a capacidade de impulsionar mudanças profundas nas estruturas sociais, políticas e econômicas do país. E é exatamente isso que os representantes do golpe 2016 querem evitar, impondo contra esta política diversos retrocessos, dentre os quais destacamos a Emenda Constitucional
95/2016 (Presidência da República, 2016), que determina que o orçamento para educação, saúde, assistência social, cultura, trabalho e renda e demais políticas sociais e econômicas está congelado por vinte anos.

Em relação às universidades públicas, a política de desmonte não foi diferente. As universidades enfrentaram, em períodos distintos, severas condições precárias (professores sem salários por meses seguidos, cortes de bolsas e serviços básicos), tendo como consequência diversas greves e suspensão de aulas. Como resultado, por um lado, trouxe muita luta e resistência à universidade; e por outro, viveu-se os dias mais críticos de toda sua história, com fuga de alunos e docentes, além de muita dificuldade para a continuação das pesquisas.

Em relação às escolas básicas, as condições de que dispunham também refletiam o quadro de dominação em prática na área. Se pegarmos, por exemplo, a região metropolitana onde a pesquisa foi desenvolvida, a cidade de São Gonçalo no Estado do Rio de Janeiro, podemos falar de inúmeros desafios socioeducacionais.

A rede escolar parceira nesta pesquisa era composta, em 2018, por 114 escolas e 34 creches conveniadas. Trata-se da segunda região mais populosa do Estado do Rio de Janeiro e está há apenas 8 pontos do último colocado no IDEB do Estado (em 2017). Em 2005 (1 ano do IDEB) 3,8; 10 anos depois, em 2015 - 4,3 (meta 5,1). Em 2017 - 4,5 (meta 5,4), 0,9 abaixo da meta.

A região, nos anos de 2016-2018, não investiu na educação valores necessários para a melhoria da qualidade de ensino e garantia de direitos dos profissionais da educação, descumprindo - Plano Municipal de Educação (PME), a Lei Municipal n. 658/2015 (Prefeitura Municipal de São Gonçalo, 2015) e o plano de carreira estabelecido em Lei Municipal n. 008/2003 (Prefeitura Municipal de São Gonçalo, 2003), que estabelecem o piso nacional do magistério, 
não remunerando os profissionais da educação condignamente.

Ainda diretamente relacionado aos desafios de uma escola democrática, está o financiamento da educação. Quanto a isso, podemos observar que a região possui desafios que precisam ser enfrentados. Os três últimos pareceres do Conselho de Acompanhamento e Controle Social do Fundo Nacional de Desenvolvimento da Educação (Fundeb) reprovaram a prestação de contas das verbas do Fundeb devido à falta de transparência na utilização dos recursos.

\section{DESAFIOS EPISTÊMICOS PARA A FORMAÇÃO DOCENTE}

O contexto sociopolítico atual é desafiante para a América Latina. A disputa entre aqueles que buscam reescrever a história do continente na perspectiva descolonizadora e os que trabalham por sua recolonização se intensifica. Diversos governos conservadores tomam o poder em condições controversas e implementam políticas de restrição de direitos, entre elas, o ataque à educação pública como direito da população. Nessas condições, as lutas docentes adquirem ainda mais destaque no centro da disputa entre os que buscam "formas justas para o mundo" e os que buscam a manutenção das desigualdades sociais.

Para a pedagogia decolonial (Oliveira \& Candau, 2010), o colonialismo foi responsável pela negação sistemática de saberes e condições de existências de todos os povos não europeus. A perspectiva refuta esta condição e afirma que a questão radical que pode reorientar os povos colonizados na direção da retomada de suas vozes e formas de vida é a pergunta por quem somos nós (quem eu sou/quem estamos sendo). A pergunta nos projeta numa direção epistêmica emancipada, pois não aceita o que dizem "os outros", mas busca em si e nos seus pares o conhecimento que permite reconhecerse portador de sua própria história. Este seria o ponto de vista decolonial: visibilizar as lutas contra a colonialidade a partir das pessoas, suas práticas sociais, saberes e políticas.

A decolonialidade representa uma estratégia que vai além da transformação da descolonização, ou seja, supõe também construção e criação. Sua meta é a reconstrução radical do ser, do poder e do saber (Oliveira \& Candau, 2010, p. 24).

Podemos pensar que a práxis que nasce na proposição decolonial representa a criação e construção de outras condições pedagógicas para professores e estudantes. Para além de processos de ensino baseados na transmissão, a pedagogia decolonial quer conceber a educação como uma política de negociação cultural, espaço de debates de saberes e distintas formas de vida.

Dialogando com esta perspectiva teórica, Sousa Santos $(2010,2018)$ afirma que estamos marcados por uma injustiça cognitiva, que vem sendo responsável pelo que denomina de epistemicídio, a morte de todas as outras formas de conhecimento que não as hegemônicas, aquelas produzidas nos centros de poder marcadamente, para o autor, capitalista, colonial e patriarcal.

Para o autor, o pensamento moderno ocidental é um pensamento abissal, que se estrutura em uma linha de distinções visíveis e invisíveis que divide a realidade social em dois universos diferentes: o dos colonizados (Novo Mundo/ este lado da linha) e o dos colonizadores (Velho Mundo/outro lado da linha) 1 . Trata-se de um modo de estruturar o conhecimento tornando inexistente todo e qualquer pensamento que não seja criado pelo outro lado da linha, ou seja, pelo Velho Mundo.

Sousa Santos afirma que "a luta paradigmática é, no seu conjunto, altamente arriscada" (2010, p. 17), o que corresponde a pensarmos 
que as inovações entendidas como rupturas paradigmáticas exigem de professores a reconfiguração de saberes e a necessidade de conviver com a transformação, com a energia emancipatória. Se pensarmos o problema da educação na sua complexidade, verificaremos que as condições para gerar as mudanças reclamadas e/ou sugeridas só se efetivam se conseguirmos realizar mudanças sistêmicas nos processos educacionais, não mudanças isoladas. Como atingir essa radicalidade? Para o autor, tratar a educação na perspectiva da ruptura paradigmática é dar-lhe uma dimensão emancipatória, o que, podemos supor, corresponde à superação do pensamento abissal.

Diante desse contexto teórico, podemos afirmar que, no Brasil, aproximar escolas de universidades nas ações de formação docente corresponde investir em comunidades epistêmicas plurais, decolonizadas, com condições de emancipar as hierarquias que sempre marcaram a universidade. Supomos que, através de relações dialógicas e democráticas entre teoria e prática, universidades e escolas, professores e estudantes avançamos na construção de um espaço formativo constituído de outro ambiente epistemológico e capaz de nos fortalecer nas lutas políticas e teóricas que enfrentamos. Transformando escolas em locais de práticas reflexivas e universidades em espaços abertos à sociedade, experienciamos a construção de um campo ampliado de aprendizagem escolar e universitário, em que a formação docente é formulada através de um trabalho cooperativado.

\section{O COLETIVO INVESTIGADOR}

É nesse contexto que nasceu a experiência que apresentamos realizada na Região Metropolitana do Rio de Janeiro (Brasil), onde um grupo de professores de 18 escolas e uma universidade pública, autointitulado Coletivo Investigador, reuniu-se com o objetivo de pesquisar as epistemologias para formação docente. Tomando o cotidiano escolar como campo de trabalho, o grupo decidiu, como primeiro exercicio investigativo, trabalhar a partir da implementação da Base Nacional Comum Curricular (BNCC) $)^{2}$, investigando as condições de que dispunham as escolas para responder à nova politica.

Aproximar escolas de universidades nas ações de formação docente corresponde a questionar a centralidade dos processos de formação de professores. Os desafios são muitos se queremos transformar escolas em locais de práticas reflexivas e universidades em espaços abertos à sociedade, e ambas em comunidades epistêmicas ampliadas.

Nóvoa (2011) e Silva Jr. (1990) destacam a dimensão coletiva da prática docente como sendo uma ação que se realiza inclusive através da colaboração. Afirmam que a complexidade do trabalho pedagógico exige que possamos desenvolver equipes pedagógicas com competência coletiva, mais do que equipes que somem competências individuais, que possam se desenvolver mutuamente como um "tecido profissional enriquecido" para o enfrentamento dos desafios comuns.

Com esses interesses foi preciso inventar espaços democráticos dentro dos sistemas de trabalho de que dispúnhamos, provocando nas instituições a promoção de espaços participativos onde pudéssemos experimentar outras formas de diálogo e enfrentamento de nossos desafios. Reunimo-nos, inicialmente, num curso de extensão, no entanto, como, metodologicamente, não acreditávamos que a universidade devesse coordenar o trabalho, assumimos em seguida o formato de um grupo de pesquisa. Queríamos a democratização de nossas condições de trabalho, estejamos nós com títulos e funções distintas. 
A dimensão coletiva nos possibilita atuar e nos formar enquanto professores a partir da relação ontológica (quem somos) e epistemológica (o que investigamos), pois ao compreender quem somos, temos a chance de instituir novas práticas (novas condições epistêmicas), e estas nos permitem transformar as condições ontológicas de que dispomos a fim de que possamos ser de outras formas. "O imbricamento entre a ontologia e a epistemologia constitui o avanço mais significativo do debate contemporâneo sobre a formação de professor" (Pimenta, 2008, p. 10).

Nessa perspectiva, tomamos como ponto de partida nosso cotidiano: o lugar onde damos forma às coisas a partir das necessidades diárias que nos desafiam. Nesse sentido, criar um ambiente de investigação coletiva e democrática entre escolas e universidade correspondeu a buscar compreender o que estávamos fazendo para sermos os profissionais que éramos. $E$ por esse aspecto, aquilo que fazíamos marcava radicalmente o que éramos, especialmente porque estávamos sempre entre aquilo que queríamos ser e o que conseguíamos ser. Nossas identidades docentes sempre provisórias se constituíam, na justa medida, daquilo que compreendíamos como sujeitos que assumiam para si a história de seu tempo, e mais ainda porque trabalhávamos para construir outros tempos e histórias para o fazer docente (Pimenta, 2008). Do contrário, acreditávamos, reproduziríamos processos tradicionais do fazer docente através da dependência, da reprodução de saberes e da colonização de nossas práticas.

A partir das contribuições de Sousa Santos (2018), referentes às Epistemologias do Sul, entendemos a necessidade de tornar pública nossas vozes, fazendo-nos conhecer as condições de vida e profissão de que dispúnhamos. Trabalhamos com conhecimentos gerados e vividos por professores em práticas educacionais concretas, e nessa perspectiva é preciso conhecer as condições de vida dos sujeitos envolvidos. Sob conjunturas desiguais, conquistar poder de formular conhecimentos sobre si e nossos mundos corresponde a um processo de decolonização, um gesto eminentemente político de constituição de sujeitos.

O Coletivo Investigador é formado por um grupo de professores e estudantes, atuantes nas cidades de São Gonçalo, Itaboraí, Niterói, Maricá e Rio de Janseiro. Constituímo-nos de $67 \%$ de professores, $22 \%$ de estudantes e $11 \%$ de estudantes e professores. Entre nós, 40\% trabalham em um só local e $36 \%$ em dois locais, sendo que $18 \%$ só estudam. O grupo é bastante diverso em relação às experiências docentes: $8,9 \%$ têm de 1 a 5 anos; $13,3 \%$, de 5 a 10 anos; $8,9 \%$, de 10 a 15 anos; $8,9 \%$, entre 15 e 20; $6,7 \%$, entre 20 e $25 ; 24 \%$, entre 25 e 30 anos de docência; $8,9 \%$ têm mais de 30 anos; $20 \%$ atuam em cargos da gestão municipal. Dentre os que estão nas escolas, $74 \%$ atuam no Ensino Fundamental, $20 \%$ na Educação Infantil, 5,7 no Ensino Superior. Em relação à formação, $2 \%$ possuem doutorado; 8,9\%, mestrado; 49\%, cursos de pós-graduação; $29 \%$ são graduados e $11 \%$ têm graduações não concluídas.

Destacamos a seguir três pontos comuns nas falas de todos os integrantes, que contribuem para a compreensão de quem somos e das condições de que dispomos:

1) Professores das escolas básicas reconhecem que a formação que tiveram não foi suficiente para dar conta da imprevisibilidade da realidade educativa que encontraram nas escolas. Por isso, admitem que buscam continuamente aperfeiçoar sua formação pedagógica, a fim de compreender a complexidade das relações entre sociedade e educação. Afirmam que a universidade é importante parceira na conquista de suas autonomias profissionais. 
2) Trabalhando em condições precárias, professores muito rapidamente se tornam insatisfeitos com suas carreiras profissionais, e, o que nos parece mais grave, veem-se com pouco instrumental para ressignificar os sentidos da prática cristalizados no seu cotidiano escolar. $\mathrm{O}$ que geralmente implica mais vulnerabilidade do fazer docente, instaurando um ciclo negativo de trabalho, que, acreditam, pode ser rompido através do trabalho conjunto desenvolvido entre escolas e universidades públicas. O que se comprova na permanência de $70 \%$ da equipe há três anos em trabalho sistemático.

3) As escolas são caracterizadas como espaços de muita contradição: se, por um lado, há no cotidiano escolar saberes e potenciais que precisam ser valorizados, revelados e amplificados; por outro, há também muita improvisação, pouca reflexão e muita precarização nas condições de trabalho.

\section{A PESQUISA-AÇÃO PEDAGÓGICA COMO OPÇÃO EPISTEMOLÓGICA}

Como temos afirmado (Moreira, 2018), a pesquisa-ação pode ser utilizada de diferentes maneiras, sob diversas intencionalidades, constituindo-se num vasto leque de abordagens teórico-metodológicas. No entanto, essa opção metodológica decerto investe no interesse de que a pesquisa e a ação devem caminhar juntas. Ao elaborar esta pesquisa, tínhamos como objetivo desenvolver uma investigação científica a partir de fontes que são historicamente construídas, como as relações de professores e estudantes com escolas e universidade, o que exigiu a reunião de condições epistemológicas capazes de auxiliar a formulação de um campo de investigação solidária, plural, criativa e aberta ao diálogo universitário e comunitário, mas principalmente capaz de transformar as condições dessas relações (Brandão, 2003).

Com base em Kincheloe (2007), entendemos que a pesquisa-ação crítica rejeita as noções positivas de racionalidade, objetividade e verdade para pressupor a explicitação dos valores dos grupos envolvidos. A metodologia não pretende apenas compreender ou descrever o mundo, mas transformá-lo. Para isto, investe na práxis do grupo, nas suas perspectivas explícitas e ocultas para, a partir delas, negociar as mudanças. Nesse sentido, enquanto práticas colaborativas, assumem o caráter crítico.

Barbier (2002) é ainda mais enfático quando se refere à natureza da pesquisa-ação. Para ele, a metodologia não quer separar os fatos e os valores, estrutura-se por dentro deles, através dos pensamentos e das ações dos integrantes, pressupondo uma integração dialética entre sujeito e sua existência, fatos e valores, pensamento e ação, pesquisador e pesquisado. A pesquisa-ação, além de questionar a epistemologia positivista, presume a necessidade de avançarmos sobre formas e modelos colaborativos no desenvolvimento de pesquisas sociais voltadas para a transformação social. Para o autor, a pesquisa-ação possui compromissos políticos e éticos, com vista à emancipação dos sujeitos e das condições que obstruem seus processos.

Neste trabalho, apoiamo-nos na Pesquisa-Ação Pedagógica de Franco (2016), que nasce nesta tradição teórica, e em especial na dimensão emancipatória formulada por Freire (1982) na Pedagogia do oprimido.

Foi através das ideias de Freire (2006) para os Círculos de Cultura, que Franco (2016) elaborou os dispositivos para a Pesquisa-Ação Pedagógica, destacando três momentos: a) a investigação temática, quando os componentes do Círculo buscam nas experiências dos participantes os temas para seus processos educativos; b) a tematização, quando o grupo decodifica estes temas; e c) a problematização ou o meio pelo qual as experiências são perspectivadas através da visão crítica em diálogo com outras referências. Nosso percurso 
metodológico foi construído sobre estas bases: partimos de nossos saberes comuns na direção da práxis, experienciando, num processo contínuo de autoconscientização, reflexões sobre nossas circunstâncias e perspectivas.

A autora afirma que a pesquisa em educação tem uma perspectiva eminentemente pedagógica, pois estuda as práticas educacionais por meio da participação dos próprios sujeitos, agindo também no campo da formação dos envolvidos, transformando-os. A pesquisa-ação voltada para a formação contínua de professores foi denominada por Franco (2016) de PesquisaAção Pedagógica, pois tem a formação como objetivo principal.

A dinâmica de um processo formativo para docentes centrado na escola, como propomos, vincula o ensino à pesquisa e a pesquisa à extensão, objetivando tornar o professor, como profissional, capaz de compreender e atuar na realidade educacional contemporânea; da mesma maneira que cria condições para a universidade expandir seu papel social. A pesquisa configura-se como espaço de formação articulado à extensão universitária, como "braços" da universidade, que, através do diálogo e de compromissos pactuados, ampliam a ação universitária para estar em algumas escolas do município. Por outro lado, busca, também, trazer para dentro da universidade o que Sousa Santos (2010) propõe como "extensão às avessas", quando se constrói condições para outros saberes e atores atuarem no interior da universidade, convidando os professores das escolas a refletirem juntos com os estudantes universitários em espaços de formação continuada (Moreira, 2018).

Quanto às fases da pesquisa, podemos dizer que, refletindo juntos, nosso pensamento foi adquirindo diferentes "formas" durante o processo, todas complementares. Baseados em Franco (2016), destacamos quatro princípios da Pesquisa-Ação pedagógica estruturantes nos processos participativos que estiveram presentes em todas as etapas:

\section{A constituição coletiva entre pesquisadores e participantes}

Em todas as fases da pesquisa, buscar constituirse enquanto coletivo investigador, identificando as trajetórias individuais e integrando-as através de interesses comuns e complementares, continuamente.

\section{Mobilização para a partilha de conhecimentos}

Trabalhar a partir das relações de sentidos, experiências, conceitos, autores de referência expressos nas diferentes abordagens, buscando a convergência para a elaboração do trabalho conjunto. Realizamos mapas conceituais de nossas experiências, procurando os aspectos comuns, aqueles que poderiam nos ajudar na elaboração de nosso objeto de investigação. A partir de conceitos identificados, selecionamos autores para nos auxiliar na compreensão do problema de pesquisa. Este trabalho foi realizado por meio de diversas dinâmicas (leituras, escritas e debates), todas visando à compreensão da complexidade dialética que nos envolvia.

\section{Consideração da complexidade do processo}

Consideramos em todas as fases a imprevisibilidade que os processos coletivos, fundamentados na práxis, mobilizam na investigação coletiva. A imprevisibilidade que os processos criativos demandam muito nos mobilizou, "os espaços" de dúvida e inquietação que precisamos suportar até conquistarmos a inteligibilidade através do coletivo geraram muita angústia no grupo, que admitia estar acostumado a executar planos previamente elaborados. A escuta solidária e a expressão de nossas diferenças foram partes fundamentais de todo nosso trabalho, alargando nossos movimentos, 
seja individualmente, seja coletivamente.

\section{A perspectiva de produção de rupturas na direção de outras dinâmicas para a formação universitária.}

Através destes princípios, a pesquisa em campo, a organização dos dados, a tarefa de sistematizar, de construir sínteses, articulá-las em novas formulações a ser apropriadas pela comunidade acadêmica, aquilo que Franco (2016) chama de "produção de rupturas cognitivas", foram os momentos em que o pesquisador/professor/estudante mudou sua concepção de profissionalidade através do trabalho de pesquisa coletivo.

A pesquisa é estruturada obedecendo às recomendações da Capes e segue as determinações éticas da pesquisa social no país, sendo cadastrada na Plataforma Brasil. Os dados obtidos por meio desta pesquisa são confidenciais e não serão divulgados em nível individual, visando assegurar o sigilo de cada participação, tanto quanto a identificação dos profissionais e estudantes como das instituições envolvidas.

Por fim, é importante afirmar que a pesquisa teve o apoio institucional da rede onde a maioria dos professores das escolas atuavam e este apoio institucional foi determinante para a participação de professores, que puderam participar de todo processo da pesquisa em horário de trabalho, bem como ser pontuados em suas carreiras (Moreira, 2018).

\section{A PESQUISA}

Fundamentados na ideia de que currículos são campos de disputas e imersos na luta pela valorização da educação pública perante os violentos ataques que sofre, organizamonos na instauração de um espaço de pesquisa coletiva entre estudantes e professores de escolas e universidade. Através desse trabalho, reagíamos diante das forças que insistem em gestar a escola sempre de fora para dentro e tomamos o cotidiano escolar como foco de atuação.

A política de implementação da Base Nacional Comum Curricular (BNCC) era, naquele período, a principal agenda de escolas no país e por isto constitui nosso problema de pesquisa. Com base em nossas práticas, procuramos identificar experiências curriculares em desenvolvimento nas escolas e como estas vivenciavam a implementação da nova base comum curricular.

O currículo se tornou um tema central na política de conhecimento do mundo capitalista, uma arena de disputas desproporcional que busca manter os povos sul-americanos na perspectiva colonizada. Nessa perspectiva, a BNCC adquire destaque na luta por uma pedagogia emancipada, decolonial. Como parte da política curricular, seus resultados são aferidos em avaliações externas aos sistemas educacionais, que respondem ao Fundo Monetário Internacional (FMI) e à Organização para a Cooperação e Desenvolvimento Econômico (OCDE), que pautam o Programa Internacional de Avaliação de Estudantes (PISA). São políticas implementadas por grupos detentores de grandes capitais que se opõem fortemente aos que oferecem resistência a seu avanço, em especial professores e estudantes da educação pública.

A BNCC é parte desta política integrando ações de Estados e governos que pautam as discussões sobre a educação, buscando não só impor uma formação voltada para o mercado como controlar docentes em salas de aula. Está estruturada com base em habilidades e competências externas a estes contextos, portanto, ignorando os cotidianos e demandas da vida comunitária onde se situam as escolas e os sistemas educacionais.

A escola vem trabalhando com um currículo oficial que valoriza muito pouco as diversas 
culturas que compõem um país tão plural como o Brasil. Assim, as pessoas vão às escolas para adquirir aquilo que é considerado apropriado nos currículos oficiais enquanto os conhecimentos das classes populares, a maioria que frequenta as escolas públicas, vão sendo negados na escola como um "não saber", embora esteja lá e apareça nas vozes dos estudantes e suas experiências.

Aqueles que têm estudado o cotidiano da escola - e da vida - sabem, no entanto, que as vozes, nos projetos dominantes, proibidas de falar, continuam falando, os sons interditados que neles circulam são ouvidos por alguém, os cheiros aí produzidos chegam a algum lugar... E é isto que tanto assusta aos que ainda detêm o poder e que tanto se aferram à ordem (Alves \& Garcia, 2008, p. 74).

Há uma tendência ainda dominante na sociedade brasileira de caracterizar a escola pública, principalmente a voltada às camadas populares, como um espaço que os estudantes precisam frequentar para obter conhecimentos "que não têm", conhecimentos de todos os tipos que lhes "farão bem" (Alves \& Garcia, 2008). Em geral, o conhecimento que entra na escola é decidido a partir de critérios exteriores a ela e, muitas vezes, por especialistas que adquiriram autoridade fora da escola. Essa escolha levou a uma fragmentação do saber, pois os conteúdos, ao ser selecionados, são retirados de seus contextos para se adaptarem a um espaçotempo escolar organizado e planificado em grades e áreas específicas, desenvolvendo abordagens indiferentes aos saberes populares.

\section{INVESTIGANDO A PRÓPRIA PRÁTICA PEDAGÓGICA}

Buscando investigar as condições de que dispunham as escolas para responder às demandas referentes à implementação da BNCC, desenvolvemos um formulário voltado para identificação das práticas curriculares inovadoras (inovadoras por relacionarem-se a saberes locais e/ou por interdisciplinaridade) nas escolas voltadas para o Ensino Fundamental.

Para realizar as pesquisas nas escolas, foram constituídos pequenos grupos que utilizaram ferramentas distintas: rodas de conversas, entrevistas semiestruturadas e análises de documentos. A escolha dependia das condições das escolas.

Nos dados reunidos, que aqui apresentamos sinteticamente, foi identificado $10 \%$ de práticas voltadas para matemática e arte; $30 \%$ para língua portuguesa e arte; $10 \%$ para educação inclusiva; $10 \%$ para língua portuguesa, ciências e artes; $10 \%$ para ciências e arte; $10 \%$ para geografia e artes e $20 \%$ para história, geografia e arte. Ou seja, em todas as escolas investigadas foi possível identificar práticas curriculares inovadoras, seja por estarem relacionadas aos saberes locais, seja por constituírem-se de práticas interdisciplinares. Este é um ponto que muito nos surpreendeu positivamente. Destacam-se, também, os muitos diálogos com as linguagens artísticas realizados pelos professores. O resultado evidencia que as escolas desenvolvem, autonomamente, muitas práticas pedagógicas capazes de ressignificar a BNCC e que a busca desenfreada por controlar os professores encontra resistências nas escolas.

Em relação às condições para a pesquisa encontradas nas escolas: $45 \%$ indicaram que havia boas ou satisfatórias condições para as relações de investigação pedagógica. Por outro lado, para $55 \%$ dos professores, há nas escolas muita resistência às demandas voltadas para investigações pedagógicas. Um dos nossos desafios foi o de promover mais espaço para a pesquisa e o debate pedagógico no cotidiano escolar. 
Ao pesquisar o assunto, nosso objetivo foi o de identificar práticas pedagógicas fundamentadas em processos de negociação de culturas, processos compartilhados e dialógicos de elaboração de aprendizagens significantes para estudantes na perspectiva do sujeito de direitos.

Perguntávamo-nos qual a nossa capacidade de resistência diante de políticas que insistiam em nos ignorar ao ser criada, mas exigia nossa participação para ser executada. Acreditávamos, com base em Alves (2018), que os cotidianos escolares são dinâmicos e não se subordinam sem provocar, por vezes, inesperadas rupturas. Por isso, voltamo-nos para nossos cotidianos e encontramos muitas ressignificações a esta tentativa de controle da prática docente.

Verificamos que a BNCC, naquele momento em fase de implementação nas escolas integrantes da pesquisa, não foi capaz de "estancar" a autonomia docente. Podemos, de certa forma, concordar que, apesar da fúria autoritária que tomou o país, foi impossível cortar completamente tudo o que havia sido criado e estava em desenvolvimento nas milhares de salas de aulas do país por seus docentes e discentes nesses últimos anos. "Nem é possível quebrar os sonhos de milhares de docentes e de milhões de estudantes por escolas melhores dos quais eles são muito bons conhecedores" (Alves, 2018, p. 53).

As políticas queriam calar estudantes e professores com uma campanha que Ihes fazia crer não serem capazes de dar conta de seus desafios, o que permitiu o surgimento de "salvadores da educação brasileira", que, num certo sentido, justifica que a escola precisa ser subordinada à ordem privatista, externa e indiferente a ela. Uma ordem que é também colonial. No entanto, aprendemos, também com esta investigação, que é possível a reação quando escolas e universidade trabalham juntas ressignificando relações marcadamente hierarquizadas que possuem.
"Tomar a vida escolar nas mãos é tarefa de educadores e de todos os democratas" (Ponce, 2018, p. 5). Nessa perspectiva, ao investigarmos as práticas curriculares das escolas, observamos que há muita luta tanto por parte de docentes como de discentes. Sim, há muita luta no campo educacional brasileiro e é urgente que seja assim, pois articulando formação à resistência, escolas e universidades, professores e estudantes, redescobrimo-nos na perspectiva decolonial e avançamos quanto às condições democráticas que buscamos.

$\mathrm{Na}$ prática, o sistema educacional brasileiro é desigual tanto nos aspectos ideológicos e políticos como na geografia global. Hill (2003) afirma que a ofensiva estratégica do campo neoliberal é dirigida para desestabilizar governos que resistem. Investem na criação de mercados competitivos para serviços públicos indiferentes às desigualdades que avançam no campo social decorrentes de corte dos gastos públicos e crises financeiras globais.

O projeto atual do capitalismo neoliberal global concebe a Educação como uma mercadoria e o professor é transformado num "perigoso trabalhador", pois é responsável pela formação da força do trabalho na qual se apoia todo o mundo capitalista. Por isto, é importante controlá-lo, observá-lo, monitorando seus resultados. O que descrevemos é referente às políticas de educação no Brasil a partir de 2015 e evidencia o que as teses de Hill (2003) afirmam: a necessidade de políticas para 0 controle de currículos e processos de ensinoaprendizagem.

É nesse sentido que compreendemos nosso papel como intelectuais capacitados para avaliar criticamente uma gama de perspectivas nas quais estamos inseridos $\mathrm{e}$, ao mesmo tempo, desafiados a agir de forma emancipada. Como professores e estudantes em trabalho de pesquisa coletiva, reconhecemo-nos em lutas epistemológicas e políticas determinantes para 
os processos de decolonização que nos desafia.

Com base em Freire (1982), Fanon (2003), Quijano (2007) e Sousa Santos (2018), compreendemos, na América Latina, o político como pedagógico e o pedagógico como político. Ação e reflexão, escolas e universidades, ao se aproximarem, tornam a práxis um exercício que as salvaguarda. No entanto, somos cautelosos em relação aos potenciais por mudanças que possuímos. Há restrições crescentes nos nossos espaços de trabalhos para o desenvolvimento de práticas democráticas e emancipatórias. Contra isso, é necessário agir não importando a escala de nosso alcance e seus impactos. A luta de professores e estudantes pela educação pública é uma gramática da qual não podemos nos afastar mesmo reconhecendo que este é um momento crítico para nosso país e para o mundo. Se somos perigosos para os capitalistas, como a veracidade com que somos atacados comprova, só nos resta exercer nosso poder e falar cada vez mais alto e em conjunto.

\section{CONSIDERAÇÕES E PERSPECTIVAS}

O exercício investigativo de repensar a formação de professores exigiu que nos posicionássemos acerca de nossa concepção de professores e de formação. Queríamos avançar coletivamente em relação às posições teóricas, que através de uma racionalidade técnica externa a nossa realidade insiste em nos formatar previamente, impedindo o desenvolvimento de nossa autonomia docente, principalmente como professores sul-americanos. Nós, professores atuantes em áreas periféricas, em continentes também periféricos, ao buscarmos superar a distância entre teoria e prática, tão comum em nosso campo de trabalho colonizado, experienciamos um processo de formação e pesquisa que nos permite ir além dos processos pedagógicos colonizados, aqueles construídos por outros a partir de realidades distintas das nossas. As adversidades que enfrentamos com trabalhos de formação coletivos nos ensinam que nossa resistência passa pela instauração de campos ampliados de investigação fundamentados na coparticipação, a colaboração e a solidariedade. Formas de existir anticoloniais e anticapitalistas que nos levam a necessárias revisões diante de atitudes marcadamente competitivas e individualistas nas carreiras docentes que nos impõem o processo de transnacionalização da educação.

Aprendemos que é preciso explorar o saber da experiência, ou seja, uma formação que seja realizada "dentro" dos contextos de trabalho através de condições de trabalho democráticas e solidárias. Acreditamos que os processos de decolonização que perseguimos dependem da instauração de políticas de aproximação entre escolas e universidades que busquem desenvolver, nas escolas, a cultura de análise de suas práticas com apoio da universidade; e nas universidades, uma formação ancorada aos desafios das escolas. A investigação que vivenciamos em conjunto nos mostrou um caminho epistemológico diferente da que vem orientandoaformaçãoprofissional de professores porque é um caminho desterritorializado, um "outro lugar" no cenário capitalista e colonial que nos marca. Através dessa experiência de pesquisa, respeitamo-nos como sujeitos de nossas próprias histórias, propiciando-nos a oportunidade de nos recriarmos frente aos processos autoritários e homogeneizadores que nos perseguem.

Através deste trabalho, iniciamos um processo decolonial, porque, ao desterritorializar a formação docente, instauramos um espaço de trabalho que não tem a universidade no centro do processo. Aventuramo-nos na direção de construirmos uma dimensão decolonial e pública para formação docente, estabelecendo conexões democráticas entre escolas e universidade, teorias e práticas. No entanto, manter este processo vivo é mais que um desafio acadêmico, é político, a escola 
precisa da articulação com a universidade para compreender-se como campo de pesquisa, como campo de aventura do conhecimento para a educação. Precisa da universidade para enfrentar os ataques que sofre e se legitimar.

Para concluir, destacamos ainda alguns impactos que, mais uma vez, comprovam as teses desenvolvidas neste trabalho: 1) a participação nesta pesquisa coordenada em conjunto com a universidade levou $40 \%$ de professores das escolas básicas a desenvolverem projetos para reingressar na universidade em programas de pós-graduação, mestrados e doutorados; e estudantes das licenciaturas a escreverem monografias sobre a experiência. 2) o trabalho impactou nas escolas a conquista por mais espaços de pesquisa pedagógica para docentes em seus cotidianos, fazendo mesmo com que algumas delas instituíssem horários fixos de trabalhos pedagógicos para professores.

A pesquisa foi atravessada todo o tempo pelas lutas sociais. Para finalizar, é preciso dizer que nos compreendemos como "professores em luta" ou "em luta formação". Em que medida a luta nos forma? Em que medida formamos a luta ao nos formar? Foi mergulhando nas contradições de nossas lutas pela educação pública que reinterpretamos nossas práticas e iniciamos um trabalho de reação coletiva diante do contexto opressor em que nosso país se encontra.

Em coletivo, aprendemos a manter nossa revolta viva através de formas solidárias de existência e aos poucos mantemos o imponderável e o devir histórico como possibilidades de nos reinventarmos tanto como sujeitos como socialmente.

\section{REFERÊNCIAS BIBLIOGRÁFICAS}

Alves, N. (2018). PNE, Base Nacional Comum Curricular (BNCC) e os cotidianos das escolas: relações possíveis? In Aguiar, M. A. da S. \& Dourado, L. F. (Orgs.). A
BNCC na contramão do PNE 2014-2024: avaliação e perspectivas. Recife: ANPAE. [Livro eletrônico].

Alves, N. \& Garcia, R. (2008). Atravessando fronteiras e descobrindo (mais uma vez) a complexidade do mundo. In (Orgs.). O sentido da escola. Petrópolis, RJ: DPA.

Barbier, R. (2002). A pesquisa-ação. Brasília: Plano.

Brandão, C. R. (2003). A pergunta a várias mãos: a experiência da partilha através da pesquisa em educação. São Paulo: Cortez.

Brasil (1988). Constituição da República Federativa do Brasil 1988. Brasília, DF: Senado.

Cara, D. (2018). O ímpeto do governo Temer em inviabilizar o direito a educação. Disponível em <https://danielcara. blogosfera.uol.com.br/>. Acesso em: 14/12/2019.

Fanon, F. (2003). Los condenados de la tierra. México: Fondo de Cultura Económica.

Franco, M. A. (2016). Pesquisa-Ação Pedagógica: práticas de empoderamento e participação. Revista de Educação Temática. Campinas, v. 18. n. 2, p. 511513.

Freire, P. (1982). Pedagogia da autonomia: saberes necessários à prática educativa. São Paulo: Paz e Terra.

Freire, P. (2006). Educação e mudança. São Paulo: Paz e Terra.

Hill, D. (2003). O Neoliberalismo global, a resistência e a deformação da educação. Revista Currículos sem Fronteiras, v. 3, n. 2. Disponível em: <http://www. 
curriculosemfronteiras.org/index.htm>.

Kincheloe, J. L. \& Berry, K. S. (2007). Pesquisa em educação: conceituando a bricolagem. Porto Alegre: Artmed.

Miguel, L. F. (2018). Dominação e resistência: desafios para uma política emancipatória. São Paulo: Boitempo.

Moreira, S. L. (2018). Escolas e Universidades em formação docente. REVISTALEPH, v. 15 , n. 30 , p. $165-186$

Nóvoa, A. (2011). Nada substitui um bom professor: proposta para uma revolução no campo da formação do professor. In Gatti, B. A. et al. (Org.), Por uma política nacional de formação de professores. São Paulo: Ed. UNESP.

Oliveira, L. F. \& Candau, V. M. F. (2010). Pedagogia Decolonial e Educação Antirracista e intercultural no Brasil. Educação em Revista. Belo Horizonte, v. 26 , n. 1 , p. $15-40$, abr.

Pimenta, S. G. (2008). Prefácio. In Leite, Y. U. F., Ghedin, E. \& Almeida, M. I. Formação de Professores: caminhos e descaminhos da prática. Brasília: Liber Livro Editora.

Ponce, B. J. (2018). O Currículo e seus desafios na Escola Pública Brasileira: em busca da justiça curricular. Revista Currículos sem Fronteira, v. 18, n. 3. Disponível em: $<$ http://www.curriculosemfronteiras.org/ index.htm>.

Prefeitura Municipal de São Gonçalo/RJ (2003). Lei n. 008/2003. Dispõe sobre o Plano de Carreira do magistério Público Municipal e Funcionários da Educação. Disponível em: <http://www.pmsg.rj.gov.br/ educacao/docs/lei08_2003.pdf>. Acesso em: 23 set. 2019.
(2015). Lei n. 658/2015. Dispõe sobre o Plano Municipal de Educação - PME. Disponível em: <http://www.saogoncalo. rj.gov.br/diario/2015_12_09.pdf>. Acesso em: 23 set. 2019.

Presidência da República (2016). Emenda Constitucional n. 95/2016. Disponível em: <http://www.planalto.gov.br/ccivil_03/ Constituicao/Emendas/Emc/emc95.htm>. Acesso em 30 set. 2019.

Quijano, A. (2007). Colonialidad del poder y clasificación social. In Castrogómez, S. \& Grosfoguel, R. (Orgs.). El giro decolonial. Reflexiones para una diversidad epistémica más allá del capitalismo global. Bogotá: Universidad Javeriana-Instituto Pensar; Universidad Central-IESCO; Siglo del Hombre Editores, p. 93-126.

Silva Junior, C. (1990). A escola pública como local de trabalho. São Paulo: Cortez.

Sousa Santos, B (2018). O fim do império cognitivo: afirmação das epistemologias do Sul. Coimbra: Edições Almedina.

Sousa Santos, B. (2010). A universidade do século XXI: para uma reforma democrática e emancipatória da universidade. São Paulo: Cortez. 